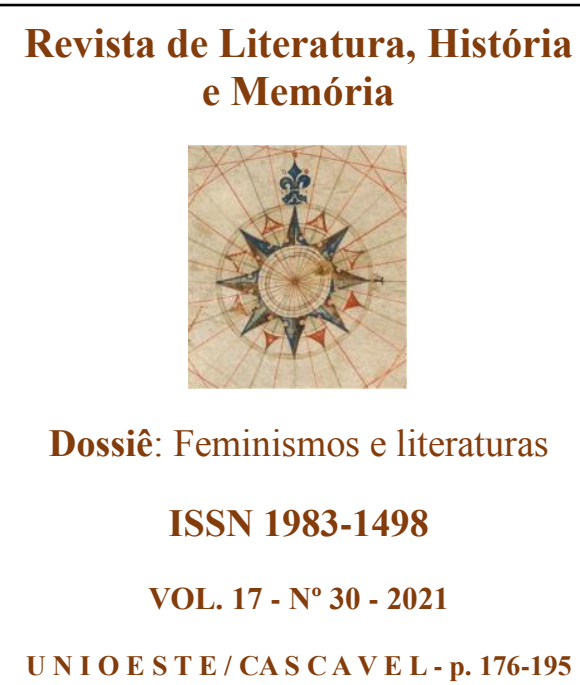

Revista de Literatura, História

U N I O E S T E / CA S C A V E L - p. 176-195

\section{UMA LEITURA DAS TRADUÇÕES CUBANA E ARGENTINA DE QUARTO DE DESPEJO SOB A PERSPECTIVA DA CRÍTICA FEMINISTA DECOLONIAL DE TRADUÇÃO}

\author{
Reading cuban and argentinian translations of Quarto \\ de despejo under a feminist decolonial translation critic
}

\section{Una lectura de las traducciones cubana y argentina de Quarto de despejo desde la crítica de traducción feminista decolonial}

\author{
Penélope Serafina Chaves Bruera ${ }^{1}$
}

RESUMO: Este trabalho visa indagar, nas traduções ao espanhol de Quarto de despejo, de Carolina Maria de Jesus do século XX, Quarto de despejo, diario de una mujer que tenía hambre, publicada em 1961 na Argentina, e Favela, publicada em 1965 em Cuba, como raça, classe e gênero conformaram um entramado estreito e indissolúvel que condicionou tanto a recepção da autora na América Latina e o Caribe, quanto o tratamento que os/as tradutores/as deram a sua obra. Ambas são examinadas sob a perspectiva da crítica feminista de tradução. Para isso, apresentamos, brevemente, a conjuntura editorial de cada caso e depois analisamos, detidamente, os paratextos elaborados pelos/as tradutores/as. Por fim, chamamos a atenção às observações dos/as diversos/as agentes literários implicados, que insistiram em remarcar a 'importância sociológica' da obra, reproduziram os erros gramaticais do texto fonte e, em consequência, se empenharam em apagar as escolhas estéticas da autora que correspondiam à linguagem da literatura clássica.

PALAVRAS-CHAVE: Carolina Maria de Jesus; Quarto de despejo; Traduções ao espanhol; Crítica feminista de tradução; Feminismo decolonial.

ABSTRACT: This paper aims to investigate the 20th century Spanish translations of Quarto de despejo by Carolina Maria de Jesus, Quarto de despejo, diario de una mujer que tenía hambre published in 1961 in Argentina and Favela published in 1965 in Cuba. Both are examined from the perspective of feminist translation criticism, with the aim of showing how race, class, and gender formed a close and indissoluble interweaving that conditioned both the reception of the author in Latin America and the Caribbean, and the treatment that translators gave to her work. For this, the editorial conjuncture of each case is briefly presented and then the paratexts elaborated by the translators are analyzed in detail. Finally, attention is drawn to the observations of the various literary agents involved, who insisted on highlighting the 'sociological importance' of her work, reproduced the grammatical errors of the source text and, consequently, strove to erase the author's aesthetic choices that corresponded to the language of classical literature.

KEYWORDS: Carolina Maria de Jesus; Quarto de despejo; Translations into Spanish; Feminist translation criticism; Decolonial feminism

RESUMEN: Este artículo propone examinar las traducciones al español de Quarto de despejo de Carolina Maria de Jesus del siglo XX, Quarto de despejo, diario de una mujer que tenía hambre

\footnotetext{
${ }^{1}$ Mestranda da PGET-UFSC. Bacharel em Letras, Artes e Mediação Cultural pela UNILA. Tem experiência em tradução no par espanhol-português e revisão de textos literários para publicação; dentre eles se destaca a tradução ao espanhol da literatura de Carolina Maria de Jesus publicada na Colômbia pela Editora Uniandes e na Argentina por Mandacaru Ediciones. Atua ativamente como tradutora e revisora no Laboratório de Tradução da Unila desde 2016, e no blog bilíngue A escrita e o fora desde 2019. Temas de pesquisa incluem gêneros literários digitais; tradução colaborativa; literaturas marginais; literatura de fronteiras; estudos de tradução feminista e decolonial.
} 
publicada en Argentina en 1961, y Favela publicada en Cuba en 1965. Ambas traducciones serán analizadas desde la perspectiva de la crítica feminista de traducción, con el objetivo de visibilizar cómo la raza, la clase social e el género forman un entramado inseparable e indistinguible que condicionó tanto la recepción de la autora en Latinoamérica y el Caribe, como el trato que sus traductores/as le dieron a su obra. Para esto, presentamos brevemente la coyuntura editorial de cada caso y después analizamos con detenimiento los paratextos elaborados por los/as traductores/as. Por último, llamamos la atención sobre las observaciones de los/as diversos/as agentes implicados, quienes insistieron en destacar la 'importancia sociológica' de la obra, reprodujeron los errores gramaticales del texto fuente y, en consecuencia, se empeñaron en borrar las elecciones estéticas de la autora que correspondian al lenguaje de la literatura clásica.

PALABRAS CLAVE: Carolina Maria de Jesus; Quarto de despejo; Traducciones al español; Crítica feminista de traducción; Feminismo decolonial.

\section{INTRODUÇÃO}

Este trabalho visa examinar as traduções ao espanhol da obra-prima da escritora Carolina Maria de Jesus, com o objetivo de visibilizar como raça, classe e gênero conformaram um entramado estreito e indissolúvel que infiltrou tanto a recepção da autora na América Latina, quanto o tratamento que os tradutores deram a sua obra. As edições que serão analisadas aqui foram publicadas na Argentina pela editora Abraxas em 1961, e em Cuba pela editora de Casa de las Américas em 1965; sendo estas as únicas traduções da obra em espanhol publicadas no século XX. O corpus de análise se constitui pelos paratextos, compostos pelos prefácios, as notas de tradução e as orelhas das edições, com adição de casos de léxico recorrentes observados no corpo da tradução. A proposta teórico-metodológica deste trabalho é abordá-las, seguindo os pressupostos da crítica feminista de tradução, contemplando os aportes de especialistas na área como Sherry Simon (1996), Carol Maier (1998), mas tendo em conta o viés decolonial dessa crítica, como apontam Claudia Costa Lima (2010; 2013), Olga Castro (2008; 2019) e a feminista decolonial María Lugones (2007; 2008; 2014). Em consonância serão retomadas as acadêmicas que têm se debruçado sobre a obra de Carolina durante a última década, como Perpétua (2003; 2014), e Fernandez (2015; 2019).

\section{A ÓTICA DA CRÍTICA DE TRADUÇÃO FEMINISTA}

A sub-representação dos sujeitos femininos na língua e na literatura foi uma questão de grande preocupação para tradutoras canadenses das últimas décadas do século $\mathrm{XX}$ (GODARD, 1990a, 1990b; LOTBINIÈRE-HARWOOD, 1991; VON FLOTOW, 1991, 1995), 
que empreenderam projetos de tradução em feminino como ato combativo contra o patriarcado. Seus trabalhos se caracterizaram pela intervenção, a visibilidade das tradutoras no texto-meta, a adoção de uma linguagem epicena, o closecolaboration com a autora e, em grande medida, a criação de um ginolecto, uma linguagem feminina que corresponda a uma experiência, em teoria, particular à mulher e, em consequência, a uma 'cultura de mulheres' como alternativa à língua patriarcal (MARTÍN RUANO, 2008). A crítica de tradução feminista vem trabalhando durante as últimas três décadas em prol de uma tradução fortemente engajada na luta pelo reconhecimento da mulher na linguagem e pela visibilidade das tradutoras, entendendo a tradução como "a mode of engagement with literature, as a kind of literary activism" (SIMON, 1996, p. IX). Existe na corrente um grande interesse em enfatizar a maneira em que as/os tradutores/as operam como agentes literários que contribuem ao debate cultural: "[t]ranslators are necessarily involved in a politics of transmission, in perpetuating or contesting the values which sustain our literary culture" (SIMON, 1996, p. IX).

A chamada escola canadense de tradução feminista, da qual Simon fez parte, tem enfrentado diversas críticas; como representar uma visão de gênero ainda pautada pelo sexo biológico 'real', materializados na genitália, extremamente excludente com respeito a identidades de gênero não binárias (que não se autopercebem nem como femininas nem como masculinas) e ainda a mulheres cujos corpos e opressões diferem daqueles corpos e opressões das mulheres do Norte Global. Ao respeito, Carol Maier (1998) lembra que a própria definição de 'mulher' é instável na discussão sobre tradução e gênero:

[...] 'woman' is not a reliable, stable point of departure for either the discussion or the practice of translation of work from any genre. On the contrary, one finds repeatedly that neither authors nor characters- and certainly not readers - conform to any fixed understanding of 'woman', even though they are defined as women by themselves or others. Perhaps more importantly, one frequently finds that even when 'woman' can be used appropriately, to use it as a single form of definition is to exclude other definitions that may be equally or more determinant [...] (MAIER, 1998, p. 98).

A desestabilização dos postulados de tradução feminista etnocêntrica cobra especial relevância nos últimos anos, quando tem sido ressignificada e reapropriada pelas tradutoras e feministas $^{2}$ do Sul Global como um espaço de resistência ao colonialismo e à modernização

\footnotetext{
${ }^{2}$ Entenda-se aqui 'tradutoras e feministas' não apenas como mulheres cis binárias, más em um sentido ampliado de mulher que contempla as diversidades LGBTIQ+.
} 
imperialista, entendendo-a como um espaço de reivindicação de 'saberes outros' historicamente invisibilizados e rejeitados pela academia (CASTRO; SPOTURNO, 2019). Como nos lembra Claudia Costa Lima, é necessário trazer a discussão dos feminismos (entendam-se os feminismos raçalizados, marxistas, indígenas, dissidentes, lésbicos e queer, por citar alguns) à ceia das instituições pós-colonias, do Norte e do Sul Global, e num gesto de traição subverter "sua gastronomia patriarcal e descolonizá-las" (COSTA, 2012, p. 45). No caso específico que concerne a este artigo, almejamos começar a visibilizar como o que María Lugones (2008) chama de Sistema Moderno/Colonial de Género operou nas duas traduções da obra de Carolina Maria de Jesus - uma feita por uma mulher e outra sob respaldo da instituição da revolução cubana Casa de las Américas - e colaboraram para uma leitura enviesada dela e de sua obra.

\section{BREVES APONTAMENTOS SOBRE CAROLINA E SUA OBRA}

Quarto de despejo, diário de uma favelada (QD) foi a primeira obra publicada de Carolina, e a que mais sucesso teve, com mais de noventa mil exemplares vendidos nos primeiros seis meses de estreia e traduções a pelo menos treze línguas (NASCIMENTO, 2009, p. 235). A obra é uma seleção de seus diários, escritos entre 1955 e 1959, organizada, datilografada e editada pelo jornalista Audálio Dantas. Inicialmente, ele publicou fragmentos dos diários em várias matérias sobre a situação dos favelados nos jornais $O$ Cruzeiro e Diário de Noite; alguns meses depois grande parte do material foi editado - segundo o prefácio escrito por Dantas, apenas teria suprimido as passagens repetitivas e arrumado pontuação e sintaxe quando necessário - para ser publicado finalmente pela editora Francisco Alves em 1960.

$\mathrm{Na}$ época dos acontecimentos Carolina morava com seus três filhos na favela do Canindé, às margens do rio Tietê, em condições de extrema pobreza e precariedade, se sustentando principalmente do trabalho como catadora de matérias recicláveis. A publicação do livro foi a consumação de dois grandes sonhos: ser escritora (publicada e reconhecida) e ter uma casa de alvenaria. Com o rápido e inusitado sucesso da obra, ela obteve os meios econômicos para sair da favela - a qual denominava o quarto de despejo de São Paulo - para o quarto de visitas - no alto de Santana, bairro da classe média alta branca. O deslocamento, porém, a colocou em um entre-lugar inesperado: uma mulher negra, mãe "solteira", morando em um bairro de "gente de bem", onde não era bem-vinda nem se sentia à vontade. No exterior, porém, seu sucesso ecoou rapidamente e em 1961, enquanto ela viajava pelo Brasil 
publicitando-o, sua escrita começava também a ser traduzida no mundo. Só nesse ano sua obra era disponibilizada "na França, Alemanha (Ocidental), Suécia, Itália, Checoslováquia, Romênia, Inglaterra, Estados Unidos, e Japão” (FERNANDEZ, 2015, p. 221).

O seguinte livro, Casa de alvenaria, diário de uma ex-favelada, foi lançado em 1961 sem o sucesso esperado e a editora Francisco Alves não voltou a publicar obras de Carolina. Embora ele tenha sido traduzido na Argentina em 1963, os livros que vieram depois Provérbios (1963) e Pedaços da fome (1965) - ainda permanecem sem traduções ao espanhol, assim como a versão póstuma dos diários sem supressões, Meu estranho diário (1996). Outra obra póstuma, Le journal de Bitita (1982) é a única exceção, provavelmente devido a ter sido publicado primeiro na França, fato que garantiu primeiro a circulação na Europa. Ele foi traduzido na Espanha pela editora Alfaguara sob título Diario de Bitita (1984) e logo depois ao português pela editora Nova Fronteira (1986). Por fora desta exceção, nenhuma obra da autora voltou a ser editada em espanhol no século XX. Foi só recentemente, em 2019, que surgiu um volume de mais de quatrocentas páginas, Cuarto de desechos y otras obras, que reuniu os livros Cuarto de desechos e Casa de Ladrillos, além dos relatos Favela e o conto ¿Dónde estáis, Felicidad?. A tradução é creditada ao Laboratório de Tradução da Unila, que foi lançada na Coleção Labirinto de Ediciones Uniandes, na Colômbia, em 2019 e na Argentina em 2021, pela Mandacaru Ediciones. Integrantes do laboratório se debruçaram sobre o complexo processo tradutório em artigo publicado pela revista Belas Infiéis (TORRES et al., 2021).

A seguir vamos examinar as traduções ao espanhol do século $\mathrm{XX}$, repassando brevemente os projetos editoriais onde surgiram, no intuito de visibilizar como o entramado de raça, classe e gênero se manifestou e, potencialmente, afetou sua recepção fora do Brasil.

\section{AS TRADUÇÕES AO ESPANHOL DA DÉCADA DE 60: DOIS PROJETOS DIFERENCIADOS}

A primeira delas a aparecer foi no país vizinho de Argentina, publicada sob o título Quarto de despejo: diário de uma mujer que tenía hambre pela editora Abraxas, em 1961. Antes de aprofundar nas decisões tradutórias e os apontamentos que aparecem no prefácio, é importante fazer uma breve menção sobre a editora, embora não foi possível recavar muitos dados sobre o projeto literário e tradutório que empreendia na Argentina. A editora independente Abraxas foi extinta em algum momento a finais do século XX, período de recrudescimento das políticas econômicas neoliberais no país. Fora dos livros de Carolina, só 
sabemos que em 1973 publicaram a tradução de Piel negra, Máscaras blancas, do pensador Frantz Fanon, fato que evidencia em alguma medida a literatura que lhes interessava colocar em circulação.

Nos anos 1960-70 seu editor era Idel Luciano Sahovaler, e sua esposa, Beatriz Broide de Sahovaler, autora do prefácio e da tradução de QD; as notas e o prefácio, assim como o fato da esposa do editor ter sido a tradutora será retomado em apartado específico, antes da análise da tradução. A obra gozou de relativo sucesso na Argentina com pelo menos cinco edições lançadas até 1962, mas cabe ressaltar que desconhecemos o volume das tiragens. Como já foi mencionado, foi a única editora hispana a traduzir seu segundo livro, mas desta vez sem creditar o/a tradutor/a; aliás, Casa de Ladrillos (1963) incorpora um apêndice com os diários de viagem de Carolina, onde relata o tour literário pela Argentina, Chile e Uruguai. A menção desta última tradução, embora sua análise fuja do escopo deste artigo, procura destacar sua importância de arquivo já que os cadernos de viagem originais não se encontram nos acervos da obra carolineana no Brasil ${ }^{3}$, nem foram publicados ainda em português. As traduções de Abraxas circulam atualmente só nos sebos literários do país.

Por sua vez a tradução cubana, Favela, é publicada com uma tiragem de dez mil cópias em 1965, ano em que a ditadura militar de Castelo Branco já tinha atingido ao Brasil e a Carolina com força, e ainda foi reeditada em 1969 (PERPÉTUA, 2003). O livro aparece como parte do projeto literário de Casa de las Américas, dentro da Colección Narrativa Latinoamericana, conta com prólogo de Mario Trejo, intitulado 'Crónica de un rencor' onde pensa as injustiças sociais que o continente tem em comum e algumas apreciações sobre a escrita carolineana, más não credita a autoria da tradução. Segundo Maria Constanza Guzmán (2015; 2017) nas traduções de Casa era costume que os intelectuais que a integravam atuassem eventualmente como tradutores/as sem ser creditados pelo trabalho, prática que ocorreu pelo menos durante os primeiros dez anos antes de ser corrigida. É importante lembrar que a editora cubana fora criada alguns anos atrás, em 1960, como parte da consolidação do projeto revolucionário e que no decorrer da década cimenta-se como antessala do 'boom' na literatura latino-americana.

A literatura difundida pela revista Casa, assim como os títulos publicados e premiados pela instituição, conquistavam um lugar central nos sistemas literários da região. A tradução,

\footnotetext{
${ }^{3}$ Atualmente o acervo da autora, composto principalmente pelos cadernos originais, se encontra custodiado no Arquivo Público Municipal Cônego Hermógenes Cassimiro de Araújo Bruonswik em Sacramento, MG; na Biblioteca Nacional de Rio de Janeiro, RJ; no Instituto Moreira Salles em Rio de Janeiro, RJ; no Museu Afro Brasil, em São Paulo, SP; no Centro de Documentação e Apoio à Pesquisa da UNESP Campus Assis, SP; e no Acervo de Escritores Mineiros da UFMG, em Belo Horizonte, MG. (https://www.vidaporescrito.com/services1)
} 
portanto, exerce um papel-chave como ferramenta na construção do imaginário de uma literatura latino-americana e caribenha. Como aponta Guzmán (2015), Casa publicou um grande volume de obras traduzidas do inglês, do francês, do português (em sua grande maioria brasileiras, mas não exclusivamente), mas também dos diferentes crioulos das ilhas caribenhas. No entanto, o esforço em relação à literatura brasileira não respondia a um projeto de tradução que refletisse as discussões do campo no Brasil, senão a um "recorte desequilibrado y azaroso, mediado por el discurso ideológico de la revolución" (MOREJÓN ARNAIZ, 2003, p. 12). Segundo Arnaiz, a editora Casa privilegiou a tradução de obras que ilustrassem os movimentos rurais, as injustiças sociais e a miséria do continente, com títulos como Vidas Secas e Cuatro cuadras de tierra, ambos lançados em 1964. Cabe ressaltar que esta última foi a primeira obra brasileira a ganhar o prêmio Casa de las Américas. Um ano depois aparece Favela, que é atualmente assinalada, junto a outras obras, como precursora da posterior institucionalização do Premio Testimonio em 1970:

[los libros] previamente premiados en Casa, así como en otros textos latinoamericanos que también eran conocidos en los círculos culturales cubanos para el final de la década de 1960, y que se tomaron como antecedentes para la institucionalización del género: Juan Pérez Jolote de Ricardo Pozas (1948), Operación masacre de Rodolfo Walsh (1957), Quarto de despejo: diario de uma favelada de Carolina Maria de Jesus (1960), Biografía de un cimarrón de Miguel Barnet (1966) y hasta los Pasajes de la guerra revolucionaria de Ernesto Guevara (1963). (BLANES, 2015, p. 195).

Considerando ter pincelado superficialmente o cenário latino-americano onde apareceu QD, a continuação vamos aprofundar nas respetivas traduções e tentar desvelar sob a lente do feminismo decolonial (LUGONES, 2007; 2008; 2014), como aparece o entramado de raça, classe e gênero.

\section{A TRADUÇÃO ARGENTINA, UM EXEMPLO DE EMPATIA POR LÁSTIMA}

Beatriz Broide de Sahovaler, uma advogada argentina branca, traduziu e escreveu o prefácio da edição argentina. Pouco sabemos dela, a maioria provem das menções que podemos resgatar dos diários de Carolina (JESUS, 1962; LEVINE; BOM MEIHY, 1999), más não é difícil imaginá-la como parte da classe média alta argentina da época, uma mulher que teve acesso ao ensino superior e fala várias línguas, provavelmente inglês e francês além do português. No entanto, foi ela quem recebeu Carolina no aeroporto de Buenos Aires, no tour literário pela Argentina, e quem resolveu os detalhes de alojamento, vestimenta e alimentação 
da autora no país (JESUS, 1962; LEVINE; BOM MEIHY, 1999). Talvez pelo fato de ser 'a esposa do editor', com todas suas implicâncias (apesar ou em consequência de ser uma mulher 'cultivada'?), ela tenha desempenhado diversos trabalhos na editora do marido, extensão imaginária da casa, considerados secundários ou de menor valor, como a própria tradução que analisaremos a seguir.

O primeiro a ser destacado sobre a tradução é que Beatriz escolhe não traduzir o título Quarto de despejo, forçando um uso da 'q' que não existe no espanhol: a questão poderia ter sido adaptada com a simples mudança de quarto/cuarto, evitando criar um distanciamento entre a obra e o leitor desde o começo. Mas logo na primeira página, antes ainda do prefácio, Beatriz esclarece a metáfora do título, propõe uma solução tradutória, e defende a não tradução alegando a qualidade estética da autora:

Quarto de despejo, título original de la edición brasileña, es la imagen creada por Carolina Maria de Jesus, es el lugar donde se tiran las cosas inservibles, el cuarto de trastos viejos que la sociedad disimula y se empeña en ignorar. El acierto logrado en la elección de este título y las dificultades en hallar un adecuado equivalente en castellano, nos han movido a conservar el mismo en la presente edición (JESUS, 1962, p. 7, grifo nosso).

Em contraponto à solução que Beatriz encontrou, 'cuarto de trastos viejos', ela a desmerece alegando a intraduzibilidade do título, da genialidade carolineana, em um movimento análogo ao que faz Audálio Dantas no prólogo que prossegue o prefácio de Beatriz na edição, onde defende a intraduzibilidade da palavra favela. Mas vamos ao prefácio, oportunidade inédita para uma tradutora na época de se colocar no texto e defender suas escolhas tradutórias. Para decepção das tradutoras feministas, ela prefere apresentar Carolina ao leitor nesse espaço, começando por quem erroneamente se acreditava 'a descubriu'. O primeiro a ser mencionado é o jornalista: “Audálio Dantas es un buen periodista. [él] puede hacer interesantes muchas cosas que para otros pasarían inadvertidas" (JESUS, 1962, p. 9). Na sequência é destacada a obra, os diários da mulher que tinha fome como um verdadeiro documento da miséria, e só depois sabemos algo da autora que não seja a pobreza: apesar de ser mãe de três filhos, ela não se casou.

O aspecto que se destaca no prefácio de Beatriz é uma lucidez inédita, ausente nos intelectuais da época que se relacionaram com Carolina, como vamos ver depois. Beatriz relaciona, por exemplo, o forte sentido de independência da escritora com sua sensibilidade e sua inteligência, apontado que apesar de sua pouca escolaridade formal -a diferença da crítica brasileira, nunca usa o termo analfabeta- Carolina faz "agudas observaciones del mundo 
exterior" em uma crítica construtiva. Ela ainda continua ressaltando que "por sobre todas las cosas Carolina nos muestra un innato sentido de la estética. ¡Quizás su obra sea el más genuino monumento que se haya realizado para honrar la belleza!” (JESUS, 1962, p. 10, grifo nosso). Quer dizer, se reconhece uma autêntica voz de poeta, um refinamento estético, por cima da importância que possam deter os diários como registro sociológico. Para finalizar, Beatriz resolve o conto da Cinderela negra com um final feliz que não existiu, contando ao leitor sobre o êxito de vendas do livro e sobre a saída da favela, destacando que agora morava em uma casa "decente y cómoda, y allí puede dar de comer todos los días a sus tres hijos" (JESUS, 1962, p. 10).

O recurso utilizado para reforçar seu valor estético, porém, advém de marcar e remarcar a situação na qual ela escreve uma denúncia "dramática y auténtica [...] de injusticias y de imperdonables postergaciones" segundo a orelha da edição. A situação que surpreende é a pesar de ela ser negra, pobre, 'sozinha', em uma situação tão desumana que "para no morir de hambre junto con sus tres hijos se vio obligada a buscar en los basurales lo imprescindible para su subsistencia" (JESUS, 1962). As últimas palavras do prefácio de Beatriz nos desvelam a origem de sua admiração pela escritora negra na vergonha de classe, na culpa de quem nunca passou fome: "pero la favela queda. Y continuará cresciendo y seguirá mostrando al sol su ignominia. Y nos hará sentir avergonzados y hasta quizás culpables, sí, culpables de tanto dolor” (JESUS, 1962, p. 10, grifo nosso)

\subsection{UMA LEITURA ATENTA DA TRADUÇÃO DE BEATRIZ BROIDE DE 1961}

Claro que Beatriz Broide pode usar palavras rimbombantes como 'ignominia', não esqueçamos que ela é advogada, porém, faz questão de sublinhar que Carolina escreve com erros de ortografia (que a edição brasileira teve a bondade de manter!) e que em sua linguagem poética usa palavras sem propriedade, que não tem lugar na favela. A seguir vemos como operou a normatização da linguagem carolineana mantendo algumas passagens, segundo o critério da tradutora seriam as de maior teor poético; apresentamos primeiro a edição em português e depois a tradução argentina:

15 de julho de 1955 - Aniversário de minha filha Vera Eunice. Eu pretendia comprar um par de sapatos para ela. Mas o custo dos gêneros alimenticios nos impede a realização dos nossos desejos. [...] Ablui as crianças, aleitei-as e ablui-me e aleitei-me. Esperei até as 11 horas, um certo alguem. Êle não veio. Tomei um melhoral e deitei-me novamente. Quando despertei o astro rei deslizava no espaço. A minha filha Vera Eunice dizia: - Vai buscar água 
mamãe! (JESUS, [1960] 2014, p. 9).

15 de julio de 1955. Cumpleaños de mi hija Vera Eunice. Pretendia comprarle un par de zapatos. Pero el costo de los alimentos nos impide la realizaciôn de nuestros deseos. [...] Lavé a los chicos, los acoste, me lavé y me acosté. Esperé hasta las 11 a un cierto alguien. Pero no vino. Tomé un mejoral y me acosté nuevamente. Cuando me desperte el astro rey se deslizaba por el espacio Mi hija Vera Eunice decía: Vaya a buscar agua, mamá. (JESUS, 1962, p. 17).

Aqui vemos como a riqueza da linguagem carolineana é aplanada com palavras comuns e correntes, longes das que ela utilizava para descrever seu cotidiano. Ao respeito existem pesquisadoras que têm se dedicado extensamente, como Raffaela Fernandez (2015) que a descreve como uma 'poética de resíduos' onde tudo o que Carolina cata o incorpora com originalidade em busca do conhecimento e a beleza; ou por Germana Sousa Pereira (2012) como uma 'linguagem compósita e fraturada' que surge da "tentativa de uma pessoa das camadas subalternas de dominar os códigos da cidade letrada" (SOUSA, 2012, p. 21).

Embora a tradução de Beatriz reconheça sua poesia, nas sucessivas escolhas e na total falta de notas de tradução - com exceção das que dizem respeito a elementos culturais brasileiros - fica aparente que Carolina não deve ousar pronunciar, nem sequer escrever, palavras que remetam à tradição literária. A edição mantém todas as referências possíveis à cultura brasileira, ainda quando existem equivalentes totalmente plausíveis no espanhol rioplatense, como 'macarrones' (hispanização de macarrão, que existe no espanhol rio-platense, mas designa uma sobremesa refinada da gastronomia francesa); feijão em vez do local 'porotos'; pinga em vez de 'caña' ou 'aguardiente'; ou fazenda com uma nota que explicita “estancias, granjas” (JESUS, 1962, p. 58). Outra hispanização aparece com 'barracones' (do pt. barraca), que funciona em função do contexto, assim como macarrones, mas Beatriz perfeitamente poderia ter escolhido 'rancho'.

De modo geral podemos dizer que a tradução argentina de 1961 tentava manter o tom poético de Carolina, mas reforça no prefácio de Beatriz Broide, no prólogo de Audálio Dantas traduzido, e nas afirmações das orelhas, não sua qualidade estética senão o valor dos diários como documento das misérias dos pobres. Embora resgatemos alguns aspectos desta edição, não podemos deixar de mencionar que este marco determinou em grande parte a forma em que os leitores se aproximaram ao livro. Especialmente ridícula resulta a leitura da escritora peronista Aurora Venturini, quem encontra o livro em um sebo de Buenos Aires e publica uma resenha intitulada La letra en la basura no jornal Página12. Sua leitura contém afirmações atravessadas por uma percepção da favela que parece ter saído da novela Avenida Brasil e não da própria obra resenhada. Ela descreve como "Un conjunto de morros forman la favela y 
crecen alzando amontonamientos que van abrazando a Río de Janeiro. Desde arriba, los favelados miran y ven a la población afortunada" (VENTURINI, 2010). No entendimento de Venturini, a obra é uma expressão de "[t]odo el contenido de este amargo continente", "manifestado, macerado y pintado por un único personaje: el Hambre" (VENTURINI, 2010). Ela não hesita em descrever a Carolina como uma "escritora primitiva y tosca, pero extraordinaria" (VENTURINI, 2010), ainda afirmando que improvisou o título do livro. Nesta resenha se percebe como quase cinquenta anos após serem lançadas, essas traduções continuam circulando, paradoxalmente 'en la basura', e autorizando um olhar lastimoso da autora.

\subsection{UMA LEITURA ATENTA DA TRADUÇÃO CUBANA DE CASA DE LAS AMÉRICAS}

La Favela, como foi mencionado antes, a edição cubana publicada em 1965, com uma reimpressão em 1969, foi principalmente destacada em sua qualidade testimonial. Cabe mencionar que poucos escritores brasileiros foram traduzidos até esse momento pela Editora Casa de las Américas, e alguns, como Jorge Amado, participavam regularmente como júri, mas nenhum dos publicados era mulher, e nenhum deles era negro. A pesar do projeto literário de Casa de las Américas ter cristalizado durante décadas um olhar da literatura grosso modo decolonial, como defende Maria Constanza Guzmán (2015) ao analisar as traduções que foram publicadas nas décadas de 60 e 70, no caso de Carolina tanto o prefácio como as notas de tradução são utilizadas para reforçar a situação marginal da autora.

Mario Trejo afirma no prefácio que a escrita carolineana é uma 'sub-literatura', “apenas grito, protesta, rebeldía" (JESUS, 1965, p. VII), fazendo eco das palavras de Dantas, quem também escreve no prólogo "[e]l libro es lo que yo digo y lo que todos dirán ahora: grito de protesta, documento enorme de angustia" (JESUS, 1965, p. 12). Segundo Trejo, subliteratura é a única que poderia surgir da 'sub-vida' que Carolina tem, e da 'sub-literatura' que ela consome. A afirmação é parcial, pois contempla só uma fração das influências estéticas de Carolina, como às radionovelas e a literatura de folhetim; como apontam Torres et al. (2021, no prelo), o que Trejo omite é que a autora também era uma ávida leitora de clássicos românticos portugueses. No entanto, Trejo se interessa em destacar que sob a influência dessa 'sub-literatura' ela produz poemas e romances sem importância, visto que o que a deslocou fora da favela foram seus diários. A diferença de Beatriz Broide, que considerava valiosa a leitura crítica do mundo feita por Carolina, para Trejo seu valor radica em "la fuerza, la crueldad, la impudicia de una materia prima al desnudo" (JESUS, 1965, p. VII), adverte, 
porém, que o testimonio deve ainda ser penteado pelo olhar crítico das/os especialistas, das/os historiadoras/es, linguistas, sociólogas/os. Os diários são, afinal, 'crónica de un rencor', própria de uma 'casa de desahogo'. Rapidamente a publicação dos romances El esclavo, María Luis e Silvio é mencionada como uma atitude "ligera, populista y típicamente subdesarrollada" (JESUS, 1965, p. XI) para se consolidar como escritora de literatura. Apesar desses livros não ter sido traduzidos e publicados pela editora, Trejo adianta que a tentativa é em vão, pois a veracidade (dada a Carolina por ser favelada e negra) não é suficiente para fazer de sua obra uma verdadeira obra literária; a cultura "es en definitiva, una cultura de productos, no de subproductos" (JESUS, 1965, p. XI, grifo nosso).

$\mathrm{Na}$ apresentação de Trejo a autora é construída como produto das estatísticas e do azar em simultâneo: após citar os níveis de pobreza do país, Carolina é descrita como "esta negra que a los 46 años se convirtió en el best-seller de 1960” (JESUS, 1965, p. IX). Impressiona então que seja negra e escritora? Uma negra bem sucedida, êxito em vendas, talvez? Que uma mulher pobre ouse 'pronunciar o clássico'? Na sequência ele nos responde "[1]a que dice frases peligrosamente ingenuas" (JESUS, 1965, p. IX). Uma leitora atenta se perguntaria quais frases, lembrando que em 1965 Carolina já publicara um livro de provérbios próprios. Desta vez Trejo não responde, mas começa a biografia da autora afirmando com ligeireza que quando jovem ela teve que decidir "o buscar hombres o hurgar en la basura" (1965, p. X). Nessas considerações se percebe o quanto o entramado entre raça, classe e gênero (LUGONES, 2007; 2008; 2014) está firmemente atrelado, e permeia sistematicamente a crítica literária construída por Casa de las Américas enquanto instituição, ainda sendo presidida por uma mulher, a 'heroína revolucionária' Haydee Santamaría, e como projeto de esquerda. Retomando a Maria Lugones (2007), se tentássemos entender o desprezo e o descaso para com Carolina porque ela era ou mulher, ou pobre, ou negra, entraríamos em um intento fútil, já que as categorias de gênero, classe e raça não podem ser entendidas individualmente sem prejudicar, e invisibilizar, às mulheres que vivem e resistem nas intersecções dessas categorias.

It becomes logically clear then that the logic of categorical separation distorts what exists at the intersection, such as violence against women of color. Given the construction of the categories, the intersection misconstrues women of color. So, once intersectionality shows us what is missing, we have ahead of us the task of reconceptualizing the logic of the intersection so as to avoid separability. It is only when we perceive gender and race as intermeshed or fused that we actually see women of color. (LUGONES, 2007, p. 193, grifo nosso). 
Também é necessário mencionar que as apreciações racistas e machistas de Trejo são fruto, parcial, da leitura do prólogo escrito por Audálio que foi traduzido e publicado na edição cubana. A mirada masculina de Dantas descreve uma jovem mulher que sai de Minas Gerais para fazer trabalhos de limpeza e cuidados -trabalhos plausíveis às mulheres negras-, e acaba sendo 'mãe solteira':

Un día todo quedó atrás, pajaritos, árboles, arroyos. [...] En 1937, sola, cogió un tren y llegó a otra ciudad, ciudad grande, tan grande y con tanta gente en la calle, que ella pensó que era día de fiesta. No lo era: era el día 31 de enero de 1937, en la ciudad de Sao Paulo. Empleada para trabajar en la cocina y en los quehaceres de las casas, fue la profesión de Carolina María de Jesús, por mucho tiempo. Carolina no se casó pero tuvo un hijo. Y ya no sirvió más para la cocina y otros quehaceres en las casas de los otros. La solución fue el barrio de indigentes, la favela. (JESUS, 1965, p. 11, grifo nosso).

A descrição de Carolina no discurso de Dantas, infantilizada, pode ser lida como a parábola da jovem ingênua que sem necessidade aparente se relacionou com homens e acabou por condenar o fruto, o filho, a viver com os miseráveis. Na leitura que Dantas faz da biografia de Carolina, deve ser marcado e remarcado o fato dela escolher não casar, e nessas condições ter um filho. A culpa, por extensão, é colocada na jovem que foi à procura do prazer, do belo, da poesia, e não no homem que a deixou grávida. Como indicam Perpétua (2002) e Fernandez (2015), grande parte da imagem de Carolina foi criada. Em um primeiro momento, através das matérias que apresentavam a favela como nunca antes vista, operação que Dantas fez durante meses; depois com as escolhas das capas dos livros, as exigências para que a autora se apresentasse aos eventos com roupas sujas e com um lenço na cabeça.

O/a tradutor/a cubano/a, embora esteja invisibilizado nos créditos, não hesita em utilizar as notas de rodapé como espaço para se posicionar, em consonância com Trejo, sobre a literatura carolineana. A metáfora criada no título, considerada intraduzível para Beatriz Broide, é simplificada em uma metonímia da autora por seu entorno, a favela. Seguindo este movimento, quem fez a tradução se empenha em marcar 'erros' na escrita de Carolina. Repetidamente ela é corrigida nas notas de rodapé sobre sua expressão das horas, como quando ela escreve '24 horas' se coloca a nota "12 de la noche. En Brasil se usan indistintamente ambas maneras de decir las horas" (JESUS, 1965, p. 21), ou no caso de ‘23:55' é corrigida por “11:55 p.m” (1965, p. 24).

Em repetidas ocasiões o/a tradutor/a sente a necessidade de observar "[e]s posible que quisiera decir [...]" (1965, p. 163), ou denunciar uma sintaxe confusa. A seguir citamos um caso dos múltiplos, sinalando primeiro o texto fonte (TF) e na sequência a tradução cubana 
(TC):

TF: puis feijão no fogo que ganhei ontem do [...]

TC: puse el frijol al fuego que conseguí ayer en [...]

NdT: Sintaxis confusa en el original. Naturalmente $<<$ puso al fuego el frijol que consiguió en...>>. (JESUS, [1960] 2014, p. 10; 1965, p. 19).

Contudo, quando no mesmo parágrafo Carolina descreve a manhã dizendo que "o sol está tepido" (JESUS, [1960], p. 10) opta-se pelo adjetivo 'tibio', muito mais corrente no espanhol do que tépido no português brasileiro. Na mesma linha podemos retomar a primeira entrada do diário, que na tradução argentina simplificava termos como abluir e aleitar, para observar que as escolhas lexicais consideradas mais 'rebuscadas' também foram neutralizadas pela edição cubana:

15 de julio de 1955. Cumpleaños de mi hija Vera Eunice. Yo pretendía comprarle un par de zapatos. Perlo el costo de los víveres nos impide la realización de nuestros deseos. [...] Lavé a los niños, los acosté, me lavé y me acosté. Esperé hasta las 11 por alguien. El no vino. Me tomé un mejoral y me acosté de nuevo. Cuando me desperté el astro rey se deslizaba en el espacio. Mi hija Vera Eunice decía: ¡Ve a buscar agua, mamá! (JESUS, 1965, p. 17, grifo nosso).

Se bem é possível objetar a presença, semelhante na tradução argentina, da poesia ao descrever como desponta o sol, após examinar casos similares nos inclinamos por responder que o que resguardou a passagem foi uma tradução letra por letra. É necessário lembrar que no Brasil o segmento citado foi declarado por Wilson Martins como comprovação de que o livro fora escrito por Dantas:

Em 1995, Martins reafirma sua crítica no mesmo jornal [Imprenssa], frisando que a narrativa "não podia ser de Carolina" porque "continha expressões rebuscadas como 'astro-rei' em vez de sol, simplesmente; ou frases inteiras, como 'acordei, abluí-me e aleitei-me'(...); só podia ser coisa de jornalista" (MARTINS, 1995, p. 4 apud FERNANDES, 2015, p. 89, grifos nossos).

Voltando à tradução em análise, podemos afirmar que economiza os esforços para recuperar as rimas, por exemplo, preferindo traduzir frases de forma literal com uma nota aludindo ao texto fonte. A graça da rima citada no Caso 1 dificilmente tenha sido recuperada pelo/a leitor/a cubano/a, mas no segundo caso ela funciona perfeitamente sem necessidade da nota: 


\begin{tabular}{|c|c|}
\hline $\begin{array}{c}\text { Quarto de despejo, diário de uma favelada } \\
\text { Texto Fonte }\end{array}$ & $\begin{array}{c}\text { La Favela } \\
\text { Trad. Casa de las Américas }\end{array}$ \\
\hline \multicolumn{2}{|c|}{ Caso 1} \\
\hline $\begin{array}{l}\text { - Sabe Carolina, eu sou um homem infeliz. } \\
\text { Depois que morreu Marina nunca mais } \\
\text { ninguém me quiz. } \\
\text { Eu dei uma risada, porque percebi que ele } \\
\text { tinha falado e formado uma quadrinha. } \\
\text { (JESUS, } 2014 \text { [1960], p. 147, grifo nosso) }\end{array}$ & $\begin{array}{l}\text { - Sabe Carolina, soy un hombre infeliz. } \\
\text { Después que murió Marina nunca más me ha } \\
\text { querido nadie. } \\
\text { Yo heché una carcajada porque me di cuenta } \\
\text { que él había hablado en verso. } \\
\text { N.d.T. Rima en el original: "Sabe Carolina. } \\
\text { eu sou um homem infeliz. Depois que morreu } \\
\text { Marina nunca mais ninguém me quiz." } \\
\text { (JESUS, 1965, p. 207-208) }\end{array}$ \\
\hline \multicolumn{2}{|c|}{ Caso 2} \\
\hline $\begin{array}{l}\text { — Ela saiu no O Cruzeiro. Com ela agora é } \\
\text { mais cruzeiro. } \\
\text { (JESUS, } 2014 \text { [1960], p. 152) }\end{array}$ & $\begin{array}{l}\text { — Ella salió en O Cruzeiro. Con ella ahora } \\
\text { hay más cruzeiro. } \\
\text { N.d.T.: Juego de palabras, cruzeiro-moneda y } \\
\text { cruzeiro-revista } \\
\text { (JESUS, } 1965, \text { p. } 214)\end{array}$ \\
\hline
\end{tabular}

Cuadro 1. Elaboração própria.

A criatividade que escasseia nas traduções citadas, porém, aparece para interpretar o que Carolina quer dizer em ceias mais domésticas, nas notas de rodapé. Por exemplo, no uso de 'batata salsa', a nota esclarece: "Solsa en el original. Subrayado por la editorial, probablemente quiso decir Ensossa: sossa” (JESUS, 1965, p. 53, itálico do original). De forma análoga, em uma passagem Carolina relata seu stock de legumes, "Yo tenía unas cebollas que Juana la de Binidito me dio porque yo le di unos tomates. Mandé a Vera a guardar los tomates y me fui a preguntarle a las mujeres que qué pasaba" (1965, p. 173). Frente à fartura da favelada com tomates e cebolas, na segunda menção dos tomates, grifada acima, a tradução a questiona com a nota “¿Cebollas?” (1965, p. 173).

Se, como fica aparente, a favelada não saberia nomear sequer os legumes, tampouco existia a possibilidade de traduzir 'abluir' por um termo igualmente refinado como 'ablucionar'. Adicionalmente, a tradução se esmera em reproduzir erros ortográficos em duas modalidades. Em alguns casos se naturalizaram dentro do corpo da tradução de uma forma assimilável aos erros ortográficos que ocorreriam no espanhol, como 'imprecioné' (impresioné), 'cosinar' (cocinar) e 'escosés' (escasez) (JESUS, 1965, p. 210; 222; 231). Em outras ocasiões, se utilizam as notas de rodapé para anunciar ao leitor/a quando ela escreve estrangeirismos seguindo sua sonoridade, como são os casos de 'gilete', 'Kubstchek', 'shou', 
'pulover' ou 'Chatobriand' (JESUS, 1965, p. 93; 101; 110; 127; 214), em uma tentativa de lembrar ativamente que a autora tem pouca escolaridade. Por vezes a sintaxe da tradução resulta desafiadora, mas seu estudo requer marco teórico-metodológico específico, que permita analisar a competência tradutória versus uma preferência pela tradução sintaticamente literal (como fez o/a tradutor/a nas notas de rodapé antes mencionadas).

\section{CONSIDERAÇÕES FINAIS}

Especialmente perturbadora para Carolina foi a visita de 1961 ao Chile. Em uma ocasião, sendo a convidada do escritor chileno Rubén Azócar, ela é alvo de comentários abertamente racistas: "El señor Benjamín Subercaseaux me dijo: - Carolina: usted puede admirar las bellezas de Chile como turista. Pero no piense en vivir aquí, porque a nosotros los chilenos no nos gustan los negros" (JESUS, 1962, p. 175). A continuação citamos algumas passagens que ilustram como a imprensa e a burguesia chilena a trataram, questionando repetidamente sua maternidade, sua falta de educação formal e sua cor de pele:

Un señor me presentó a los periodistas explicando que no soy casada y tengo tres hijos y etc... Comentaban horrorizados que la sociedad debía repudiarme porque no me casé. Que no debían prestarme atención. [...] Fui entrevistada por un periodista brasileño. En el reportaje él dijo que soy prácticamente analfabeta y de un corazón muy bueno ¡Muchas gracias señor periodista! [...] La dueña de la casa no nos miró. Ni me acompañaron hasta la puerta. Es falta de educación invitar a una persona a visitar nuestra casa y no prestarle atención. ¿Pero quién soy yo? Una mujer de la favela, una mujer que no está casada no puede dar una lección de etiqueta a una señora de la sociedad $[. .$.$] ¿Será que en Chile no hay madres solteras?$ $¡ O$ quizás Chile sea el país de la pureza! [...] En los reportajes que las revistas de Chile publicaron sobre mi dicen que no tengo educación. Pero yo no bebo. No fumo. No me gusta bailar. No tengo ambición desmedida. Solamente me gustan los libros. Todos nosotros tenemos libre arbitrio. Yo soy una escritora que ama a los pobres. Los pobres tienen un lugar destacado en el corazón del poeta. Dicen que yo no tengo educación. Pero no todos los que recibieron una gran educación favorecieron a su patria ni a los humildes Yo trato de ayudar a solucionar los problemas del pueblo. [...] (JESUS, 1962, p. 169-177, grifos nossos).

No ano seguinte, quando Carolina fora convidada novamente ao Chile à Séptima Escuela Internacional de Verano de 1962, um encontro internacional de intelectuais, embora os comentários não tenham se repetido - ou ela omitiu registrá-los -, e apesar de proferir o discurso América necesita otra Independencia, sua presença é esquecida pelos pesquisadores quando se analisa a importância conjuntural da Escuela de Verano em relação aos intelectuais 
latino-americanos que lá se reuniram. No encontro de 1962 ela compartilhou mesas de debate e noites de festa com personalidades da região como Octavio Paz, Alejo Carpentier, Pablo Neruda, Carlos Fuentes, Augusto Rosa Bastos e José María Arguedas. Como ela atesta em seus diários de viagem, as outras mulheres presentes - nenhuma delas negra -, eram esposas dos palestrantes, secretárias ou assistentes. Seu discurso, sua denúncia, rapidamente foi desmerecida e para meados de 1962 seu único ingresso econômico provia dos direitos autorais das traduções (LEVINE; BOM MEIHY, 1999).

O material escolhido para publicação não era aquele que Carolina escrevera durante anos em centos de cadernos em um acervo que compreende poesias, contos, obras de teatro, músicas e relatos diversos. Eles não tinham o valor estético que procuravam os críticos brasileiros nem o refinamento literário que se vislumbrava na produção das mulheres escritoras na época, como Clarice Lispector. A produção carolineana não fora considerada suficientemente literária, mas seu olhar sociológico da favela, como limos no prefácio da tradutora argentina, era causante de culpa. Esta leitura marcou sua obra seguinte, na construção de uma produção que nunca deixou de ser lida como uma autobiografia dos miseráveis enquanto autoetnografia desde dentro da favela; podemos ilustrar este ponto examinando os títulos e subtítulos escolhidos para publicar seus livros: diário de uma favelada; diário de uma ex-favelada; pedaços da fome; estranho diário; diário de Bitita. A marca do gênero testimonial do diário ou a da miséria só estão ausentes em Provérbios, financiado pela autora e publicado por uma editora independente, mas que não foi bemsucedido nas ventas.

Para melhor entender as implicações do ocorrido no Chile, assim como no manuseio dos diários e suas traduções, é necessário entender o caráter sistêmico, colonial e patriarcal manifesto no estreito entramado entre gênero, classe e raça segundo entendido por María Lugones (2008; 2014). Sob esta lente podemos dizer que não é por ser mulher $e$ negra, ou mulher $e$ pobre que Carolina enquanto escritora causa um incómodo difícil de assimilar até por suas tradutoras/es, mas justamente pelas implicações da preta pobre na sala de visitas. A voz de Carolina é questionada enquanto única mulher entre homens intelectuais; sendo a única pessoa negra presente, ela é uma raridade incômoda; sua presença nas conferências e seu interesse nas questões da política internacional são lidas como evidencias de uma escassa inclinação com tarefas de cuidado e reprodução. No espaço simbólico da sala de visitas, ela continua sendo a vizinha que não se encaixa, o subalterno que grita, um sujeito não desejado, que interessa em sua capacidade de representar a miséria das periferias em uma performance desumanizadora: a catadora de lixo suja, semianalfabeta com o lenço na cabeça. No bairro de 
classe média e no salão dos intelectuais, seu trabalho como escritora, as aparições na mídia, as viagens de avião, as lições para aprender a dirigir, são lidas como uma transgressão insuportável, totalmente incompatíveis com a maternidade e com seu papel de advogada dos favelados.

\section{REFERÊNCIAS BIBLIOGRÁFICAS}

BLANES, Jaume Peris (org). El premio Testimonio de Casa de las Américas. Conversación cruzada con Jorge Fornet, Luisa Campuzano y Victoria García. Kamchatka, [S. l.]. 6, dez. 2015. Disponível em: https://ojs.uv.es/index.php/kamchatka/issue/view/540. Acceso em: 27 jun. 2021.

CASTRO, Olga. Género y traducción: elementos discursivos para una reescritura feminista. Lectora, Barcelona, n. 14, p. 285-301, 2008. Anual. Disponível em: https://revistes.ub.edu/index.php/lectora/article/view/7155 Acesso em: 28 jun. 2021.

CASTRO, Olga; SPOTURNO, María Laura. Feminismos y traducción: apuntes conceptuales y metodológicos para una traductología feminista transnacional. Mutatis Mutandis, v. 13, n. $1,2019$.

COSTA, Claudia de Lima. Feminismo e tradução cultural: sobre a colonialidade do gênero e a descolonização do saber. Portuguese Cultural Studies, v. 4, 2012.

FERNANDEZ, Raffaella. A poética de resíduos de Carolina Maria de Jesus. São Paulo: Aetia Editorial, 2019.

FERNANDEZ, Raffaella. Processo criativo nos manuscritos do espólio literário de Carolina Maria de Jesus. 2015. 315 p. Tese (Doutorado em Teoria e História Literária) Universidade Estadual de Campinas, Campinas, 2015. Disponível em: http://repositorio.unicamp.br/jspui/bitstream/REPOSIP/270193/1/Fernandez_RaffaellaAndrea D.pdf Consultado el 15 jun. 2021.

GODARD, Barbara. Theorizing Feminist Discourse/Translation. In: BASSNETT, Susan; LEFEVERE, André (eds.). Translation, History, Culture. Londres e Nueva York: Pinter Publishers,

1990.

GODARD, Barbara. Preface to LoVhers, by Nicole Brossard, trans. Barbara Godard, Montreal: Guernica, 1990.

GUZMÁN, María Constanza. El Caribe se traduce: la traducción como praxis descolonial en las revistas Tropiques, Bim y Casa de las Américas. Mutatis Mutandis, v. 10, n. 1, 2017.

GUZMÁN, María Constanza.Vectors of Exchange: Translation Praxis in Cuadernos de Marcha and Revista Casa de las Américas. TTR, v. 28, n. 1-2, 2015

JESUS, Carolina Maria de. Casa de ladrillos. Buenos Aires: Abraxas, 1963. 
JESUS, Carolina Maria de. La favela. La Habana: Casa de las Américas, 1965. Prólogo de Mario Trejo.

JESUS, Carolina Maria de. Quarto de Despejo: diario de una mujer que tenía hambre. Buenos Aires: Abraxas, 1962. Quinta edição. Tradução e prefácio Beatriz Broide de Sahovaler.

LEVINE, Robert M.; MEIHY, José Carlos Sebe Bom. The Unedited Diaries of Carolina Maria de Jesus. Trad. Nancy P. S. Naro e Cristina Mehrtens. New Brunswick, New Jersey, London: Rutgers University Press, 1999.

LOTBINIÈRE-HARWOOD, Susanne de. Re-belle et infidèle/The Body Bilingual. Quebec: Women's Press. 1991

LUGONES, María. Colonialidad y género. Revista Tabula Rasa, Bogotá, n. 9, jul-dic. 2008.

LUGONES, María. Heterosexualism and the Colonial/Modern Gender System. Hypatia, v. 22, n. 1, 2007.

LUGONES, María. Rumo a um feminismo decolonial. Estudos Feministas, Florianópolis, v. 22, n. 3, setembro-dezembro, 2014.

MAIER, Carol. Issues in the Practice of Translating Women's Fiction. Bulletin of Hispanic Studies, 75, 1998, 95-108.

MARTÍN RUANO, María del Rosario. La resistencia al trasluz: la traducción feminista en examen. DeSignis: Publicación de la Federación Latinoamericana de Semiótica (FELS), n. 12,2008

MARTINS, Wilson. Lenda Carolina: Mitos e equívocos envolvem a vida da autora de "Quarto de despejo". Jornal do Brasil. Ideias/Livros, p.4, 29 de abril de 1995.

MOREJÓN ARNAIZ, I. La literatura brasileña en los años 60 desde Casa de las Américas y Mundo Nuevo. Brazilian Journal of Latin American Studies, [S. l.], v. 2, n. 2, 2003. Disponível em: https://www.revistas.usp.br/prolam/article/view/83033 Acesso em: 9 jun. 2021.

NASCIMENTO, Érica Peçanha do. Vozes Marginais na Literatura. Rio de Janeiro: Aeroplano, 2009.

PERPÉTUA, Elzira Divina. A vida escrita de Carolina Maria de Jesus. Belo Horizonte: Nandyala, 2014.

PERPÉTUA, Elzira Divina. Aquém do Quarto de Despejo: a palavra de Carolina Maria de Jesus nos manuscritos de seus diários. Estudos de Literatura Brasileira Contemporânea, Brasília, n. 22, janeiro/ junho, 2003.

PERPÉTUA, Elzira Divina. Produção e recepção de Quarto de Despejo, de Carolina Maria de Jesus: relaçoes publicitárias, contextuais e editoriais. Em tese, Belo Horizonte, v. 5, dez, 2002. 
RODRÍGUEZ TORRES, Mario; OLIVEIRA, Bruna Macedo de; CHAVES BRUERA, Penélope. Desplazamientos de Carolina en Hispanoamérica: algunos apuntes a partir de las traducciones de Quarto de despejo al español. Belas Infiéis, Brasília, v. 10, 2021. Disponível em: https://periodicos.unb.br/index.php/belasinfieis/article/view/32802. Acesso em 27 ago. 2021.

VENTURINI, Aurora. La letra en la basura. Buenos Aires, Página12. Disponível em: https://www.pagina12.com.ar/diario/suplementos/las12/13-5739-2010-05-21.html. Acesso em 27 jun. 2021.

VON FLOTOW, Louise. Feminist Translation: Contexts, Practices and Teories, TTR, v. 4, p. 69-85, 1991.

VON FLOTOW, Louise. Dis-unity and Diversity: Feminist Approaches to Translation Studies. In: BOWKER, L et al (eds.). Unity in Diversity? Current Trends in Translation Studies. Manchester: St. Jerome. 1998, p. 3-13. 